\title{
Climate Policy with Tied Hands: Optimal Resource Taxation Under Implementation Lags
}

\author{
Corrado Di Maria ${ }^{1}$ - Sjak Smulders ${ }^{2}$ • \\ Edwin van der Werf ${ }^{3}$
}

Accepted: 26 September 2016 / Published online: 28 November 2016

(C) The Author(s) 2016. This article is published with open access at Springerlink.com

\begin{abstract}
In the presence of implementation lags, announced Pigouvian taxation leads to fossil fuel prices that are too low from society's perspective. This results in excessive emissions and reduced incentives for green innovation. Such effects are compounded by the presence of pre-existing subsidies to fossil fuel use. We show that the intertemporal resource tax path may need to be modified to optimally take into account the perverse incentives from policy lags and pre-existing policies. We find that it might be optimal to subsidize, rather than tax resource extraction at the instant of implementation.
\end{abstract}

Keywords Climate policy $\cdot$ Second-best $\cdot$ Carbon tax $\cdot$ Non-renewable resources $\cdot$ Resource taxation $\cdot$ Implementation lag $\cdot$ Green Paradox

JEL Classification Q31 - Q41 · Q54 - Q58

We would like to thank Julien Daubanes, Reyer Gerlagh, Michael Hoel, Larry Karp, Cees Withagen and two referees for their helpful comments. All authors are also affiliated with CESifo. Corrado Di Maria is a CESifo Research Network Affiliate, Sjak Smulders and Edwin van der Werf are CESifo Research Network Fellows.

Corrado Di Maria

c.di-maria@uea.ac.uk

Sjak Smulders

j.a.smulders@tilburguniversity.edu

Edwin van der Werf

edwin.vanderwerf@wur.nl

1 School of Economics, University of East Anglia, Norwich Research Park, Norwich NR4 7TJ, UK

2 Tilburg Sustainability Center, Department of Economics, and CentER, Tilburg University, P.O. Box 90153, 5000 LE Tilburg, The Netherlands

3 Environmental Economics and Natural Resources Group, Wageningen University, P.O. Box 8130, 6700 EW Wageningen, The Netherlands 


\section{Introduction}

The need to foster an environmentally sustainable process of economic growth has been the focus of much economic debate since at least the 1980's (e.g. WCED 1987). Recently, this debate has been re-cast in terms of supporting a shift towards 'Green Growth' (OECD 2011; UNEP 2011), generally understood to be about "fostering economic growth and development while ensuring that natural assets continue to provide the resources and environmental services on which our well-being relies" (OECD 2011, p. 18). Such a profound transformation, it is argued, calls for policies that would "foster investment and innovation which will underpin sustained growth and give rise to new economic opportunities, (OECD 2011, p. 18).

A crucial role in promoting green technological change is played by the price of polluting inputs. Both the theoretical (e.g. Acemoglu et al. 2012) and the empirical literature (e.g. Popp 2002; Calel and Dechezleprêtre 2016; Noailly and Smeets 2015; Aghion et al. 2016) show that a high price of polluting inputs relative to cleaner factors of production supports the development of clean technologies.

Policies that imply a decrease in the price of polluting inputs can hence have as an unintended consequence a slowing down of the process of transition from current growth patterns to more virtuous ones. One is immediately lead to think of the much debated, notorious energy subsidies that make fossil-based energy 'too cheap' (Davis 2014; Coady et al. 2015). There are, however, situations where even environmentally motivated policies may lead to reductions in prices. Policies that reduce the future profitability of a stock of a non-renewable resource, for example, may lead to a price reduction in the short run and to the front-loading of resource use, a 'Green Paradox' (e.g. Sinn 2008; Gerlagh 2011; Van der Ploeg and Withagen 2012). The presence of implementations lags in policies that make future fossil fuel use less attractive - climate change mitigation or acid rain policies, for example-induces an initial reduction in the price of fossil fuels (Di Maria et al. 2012, 2014a, b).

In this paper, we discuss how pollution policy design needs to be adapted in the presence of a policy implementation lag when emissions stem from the consumption of a non-renewable resource. In particular, we investigate second-best climate change policy when a substantial implementation lag co-exists with pre-existing suboptimal policies. ${ }^{1}$ In our model, carbon emissions are a by-product of the use of a non-renewable resource, and damages arise from the accumulation of a stock of carbon in the atmosphere. We assume that the policy-makers can credibly commit to a future policy—for example by establishing legally binding targets. We introduce policy lags by requiring that, once the new policy is enshrined in law, it can only be modified with a (sizeable) lag, e.g. due to the complexities of the political process. We also explicitly allow for the presence of pre-existing taxation or, more realistically in the case of fossil fuels, subsidies. In this context, we show that the (second-best) optimal tax needs to be adjusted in order to correct for both the marginal damages accrued during the interim phase, and the distortion to the private returns to extraction caused by the pre-existing policies. The optimal second-best tax becomes negative, i.e. resource owners receive a subsidy to extraction once regulation becomes effective, when the net present value of interim phase damages and pre-existing subsidies is sufficiently high. We also find that, contrary to the case of the optimal first-best resource tax, the second-best tax is unique.

\footnotetext{
1 Our focus on implementation lags is justified by the observation that policy lags are pervasive in the real world, and that inside lags, i.e. the time between the political decision to introduce a policy and its final implementation, are particularly long. The lags of environmental policy-especially internationally coordinated policy efforts - seems to be rather extreme. The Kyoto Protocol, for example, was signed in 1997, entered into force in 2005, and had its first commitment period only in 2008.
} 
This paper contributes to different strands of the literature. First, it contributes to the literature on optimal taxation of non-renewable resources in the presence of stock externalities by introducing unavoidable implementation lags. ${ }^{2}$ Few papers to date have discussed the effects of implementation lags in the context of non-renewable resource taxation. Di Maria et al. (2012) study implementation lags in climate policy using a model with multiple nonrenewable resources, and focus on the case of a constant, exogenous cap on the flow of emissions. They show that emissions increase in the period between the announcement of the cap and its implementation. Eichner and Pethig (2011) use a two-period, three-region model with non-renewable resources and show, among other things, that an expected, exogenous tightening of the (unilateral) second-period cap by one of the countries, might lead to a global increase in emissions in the first period. Relative to these earlier contributions, our emphasis is on optimal (rather than exogenous) policy in the presence of implementation lags. Second, our abundance effect is in the spirit of the 'Green Paradox' literature started by Sinn (2008). In this context, we are one of the first papers to discuss exhaustible resource taxation in a second-best world. ${ }^{3}$ Van der Ploeg (2016) treads on similar ground, although his analysis focuses mostly on international aspects such as carbon leakage.

The rest of the paper is organised as follows. In Sect. 2 we present the first-best outcome, i.e. optimal taxation in the absence of an implementation lag, to be used as a benchmark. Section 3 contains the derivation the optimal second-best pollution tax to be announced at the start of the planning horizon and implemented with a lag. Subsequently, we discuss its properties and the conditions under which it becomes a subsidy. We conclude with a discussion of the possible effects of pre-existing fossil fuel subsidies on optimal policies.

\section{The First-best Optimal Policy Without Implementation Lags}

Our discussion in this paper focuses on the optimal way to correct the negative environmental externality associated with the use of fossil fuels in the presence of implementation lags. In what follows, we model the behaviour of an Environmental Protection Agency (EPA), tasked with designing the tax path that allows to internalise the externality but faced with the impossibility to change existing taxes until some time, $T$ say, in the future. ${ }^{4}$

Before delving into the tax design under implementation lags, however, it is useful to briefly present the solution to the EPA's problem when no implementation lag exists, i.e. when $T=0$. In this case, the regulator can fully correct the stock externality and the first-best is achieved (see e.g. Withagen 1994; Tahvonen 1997). Letting $U(\cdot)$ denote the utility derived from resource consumption at time $t, R(t)$, with $U^{\prime}>0, U^{\prime \prime}<0$, and $\lim _{R \rightarrow 0} U^{\prime}(R(t))=\infty$, and $D(\cdot)$ indicate welfare losses from the stock of pollution, $Z(t)$, with $D^{\prime}<0, D^{\prime \prime} \geq 0$, the maximand for the EPA is,

$$
\int_{0}^{\infty}[U(R(t))-D(Z(t))] \mathrm{e}^{-\rho t} \mathrm{~d} t,
$$

\footnotetext{
2 Seminal contributions to the literature on optimal taxation of non-renewable resources in the presence of stock externalities include D’Arge and Kogiku (1973), Forster (1980), Sinclair (1992), Ulph and Ulph (1994), Withagen (1994), Hoel and Kverndokk (1996), and Tahvonen (1997). For a thorough and up-to-date review of this literature, the reader is referred to the recent contribution of Gaudet and Lasserre (2015).

3 We study the second-best situation where a policy maker's hands are tied for a given period of time, and she can only attempt to correct for near-term emissions by managing expectations about future policy. Others have analyzed second-best climate policy with limited availability of policy instruments rather than with implementation lags, e.g. Grimaud et al. (2011) and Mattauch et al. (2015).

4 In the rest of the paper we use the terms 'EPA' and 'regulator' interchangeably.
} 
where $\rho$ is the EPA's 'social' discount rate. In what follows it will be sometimes expedient to assume that the damage function is linear in the stock of pollution, in these case we will assume that $D(Z(t))=\alpha Z(t)$ so that the marginal damage of pollution $D^{\prime}(Z(t))$ is constant and equal to $\alpha$.

The EPA needs to take into account the finite supply of the resource, the initial stock of which is $S(0)=S_{0}$, and its non-renewable nature, so that ${ }^{5}$

$$
\dot{S}(t)=-R(t), \quad S(t) \geq 0 \text {, and } S(0)=S_{0} .
$$

Pollution emerges as a by-product from the use of the resource and accumulates in the atmosphere, decaying at a constant rate, $\delta>0$, over time. It follows that the law of motion for the stock of pollution in the atmosphere is

$$
\dot{Z}(t)=R(t)-\delta Z(t) \text {, with } Z(0)=Z_{0} .
$$

Taking these two constraints into account, the EPA's maximization of (1) entails the familiar static optimality condition requiring the equality between the marginal utility of consuming an additional unit of the resource and the marginal (opportunity) cost of doing so,

$$
U^{\prime}(R(t))=\lambda(t)+\tau(t) .
$$

Here $\lambda(t)$ is the costate variable to the resource stock $S(t)$ or scarcity rent, and $\tau(t)$ is the negative of the costate variable to the stock of pollution $Z(t)$ or shadow cost of pollution. The evolution of the costate variables is characterised by:

$$
\widehat{\lambda}(t)=\rho,
$$

and

$$
\widehat{\tau}(t)=(\rho+\delta)-\frac{D^{\prime}(Z(t))}{\tau(t)} .
$$

After taking growth rates in (4) and substituting (5), we find

$$
\left(\overline{U^{\prime}(R(t))-\tau(t)}\right)=\rho .
$$

We can integrate (6) using the relevant transversality condition

$$
\lim _{t \rightarrow \infty} \tau(t) \mathrm{e}^{-\rho t}=0
$$

to obtain

$$
\tau(t)=\int_{t}^{\infty} D^{\prime}(Z(s)) \mathrm{e}^{-(\rho+\delta)(s-t)} \mathrm{d} s
$$

which informs us that along the optimal, first-best path, the shadow cost of pollution equals the present value of future damages from a marginal increase in the stock of pollution at time $t$. In the case of constant marginal damages, the expression evaluates as $\tau(t)=\alpha /(\rho+\delta)$, which is a constant.

From (2), (7), (9) and the transversality condition for the resource stock (omitted) we obtain the initial value of the scarcity rent $\lambda(0)$ and the extraction path $R(t)$. Since $\lim _{R \rightarrow 0} U^{\prime}(R(t))=\infty$, the full resource stock is exhausted asymptotically along the optimal path, and $S(t)$ and $Z(t)$ both approach zero as $t$ diverges to infinity (e.g., Tahvonen 1997 , p. 859).

${ }_{5}$ In what follows, for any variable $x$, we define $\dot{x}(t) \equiv \mathrm{d} x(t) / \mathrm{d} t$ and $\hat{x}(t) \equiv \dot{x} / x(t)$. 
It is straightforward to show that the first-best extraction path can be decentralised by a resource tax that follows (6). Consider first the resource sector. Assuming away extraction costs, resource owners maximise the discounted value of their revenues net of the resource tax. Letting $p$ be the market price of the resource and $\theta$ the resource tax, resource owners are indifferent between extracting at any point in time if

$$
\overline{(p(t)-\theta(t)})=r(t)
$$

where $r$ is the private discount rate. Their transversality condition implies either non-negative profits from extraction and asymptotically full depletion:

$$
p(t) \geq \theta(t), \lim _{t \rightarrow \infty} S(t)=0,
$$

or no extraction, $S(t)=S_{0}$, and negative profits from extraction, $p(t)<\theta(t)$.

Resource users maximise their utility subject to their budget constraint,

$$
\dot{A}(t)=r(t) A(t)-p(t) R(t)+L(t),
$$

where $A(t)$ is the stock of assets held by the representative consumer, with $A(0)=A_{0}$ given, and $L(t)$ is a lump-sum transfer received by the household from the regulator (paid by the household if negative). Optimality of the resource extraction and consumption paths requires the Ramsey rule

$$
r(t)-\widehat{p}(t)=\rho-\widehat{U^{\prime}(R(t))} .
$$

Making a convenient choice of numeraire so that $p(t)=U^{\prime}(R(t))$, we get immediately that $r(t)=\rho$. Combining this with (10) and (12) shows that the optimal resource consumption path for the private sector evolves according to

$$
\left(\overline{U^{\prime}(R(t))-\theta(t)}\right)=\rho .
$$

Comparing this last expression with (7), we immediately find how the regulator's preferred extraction path can be decentralised. In particular, the optimal extraction path and the market extraction path coincide if from time zero onwards the following tax path is imposed (and fully anticipated by the market participants):

$$
\theta(t)=\tau(t)+\phi_{0} \mathrm{e}^{\rho t} .
$$

Interestingly, the unique optimal extraction path can be implemented in the market via any one of infinitely many resource tax paths defined above, i.e. there is no unique value for $\phi_{0}$. Indeed, using (14) and (13), we see that the following holds for any two arbitrary points in time $t_{1}$ and $t_{2}$ :

$$
\left[U^{\prime}\left(R\left(t_{1}\right)\right)-\tau\left(t_{1}\right)-\phi_{0} \mathrm{e}^{\rho t_{1}}\right] \mathrm{e}^{-\rho t_{1}}=\left[U^{\prime}\left(R\left(t_{2}\right)\right)-\tau\left(t_{2}\right)-\phi_{0} \mathrm{e}^{\rho t_{2}}\right] \mathrm{e}^{-\rho t_{2}}
$$

and the terms with $\phi_{0}$ cancel so that the expression coincides with (7). Intuitively, since the net present value of the tax (or subsidy) bill is constant over time for each level of $\phi_{0}$, the additional tax is non-distortionary and intertemporal resource extraction is unaffected by the tax. Notice, however, that each level of $\phi_{0}$ leads to a different level of tax revenue from the point of view of the regulator, which comes at the expense of rents otherwise accruing to the resource owners (see, e.g., Burness 1976, for a related result). Furthermore, the initial value of the tax, $\phi_{0}$, must be sufficiently low to prevent negative profits and zero extraction. ${ }^{6}$

6 The net present value of profits for resource owners is $\left[\lambda(0)-\phi_{0}\right] \int_{0}^{\infty} R(t) \mathrm{d} t$. We derive this from (10), which implies $\int_{0}^{\infty}(p(t)-\theta(t)) R(t) \mathrm{e}^{-r t} \mathrm{~d} t=(p(0)-\theta(0)) \int_{0}^{\infty} R(t) \mathrm{d} t$; substituting (14), the numeraire choice and (4), we see that positive profits require $\phi_{0}<\lambda(0)-\tau(0)$. 


\section{The Second-Best: Optimal Policy with an Implementation Lag}

While the case discussed above is a useful benchmark to aspire to, as the regulator is able to bring about the optimal outcome, it is unattainable in the presence of policy lags. As discussed in the introduction, the historical record suggests that there are significant lags between the political decision to regulate polluting emissions and the actual implementation of the policy. In the presence of such unavoidable implementation lags, the planner is simply unable to modify existing regulations for a substantial period of time, until time $T$, say.

Policy lags also rule out as infeasible the potential strategy whereby the EPA does nothing until time $T$ and then unexpectedly implements the tax path described in (14). With implementation lags, surprises are simply impossible since the tax has to be discussed and approved, before being implemented $T$ periods later. But even if possible, it would not be particularly attractive to confront the market with a tax by surprise, since, although this does internalize damages from emissions from that moment in time, it does not account for the fact that during the entire interim phase (i.e. the period up to time $T$ ) emissions are too high from a planner's perspective as extraction and emissions follow a 'laissez faire' path.

An alternative strategy is to announce at $t=0$ a Pigouvian $\operatorname{tax} \theta(t)=\tau(t)$ for all $t \geq T$ and implement it from instant $T$ onward. This, however, leaves resource owners free to adjust their extraction path in anticipation of the expected future regulation. Given that the announced policy reduces expected profits from time $T$ onwards, resource owners adjust their extraction profile before the rules come into force. It follows that extraction and emissions are higher in the interim of the regulation than they would have been in the absence of the policy. This is the so-called 'abundance effect' associated with implementation lags already discussed in Di Maria et al. (2012).

Intuitively, a regulator with perfect foresight would want to improve upon this outcome by attempting to limit damages in the interim phase. Moreover, we would expect that the stronger the supply response on the part of the extractors and the larger the damages from interim-phase emissions, the more forceful the regulator's response. In the rest of this section, we show that both these insights are supported by our formal analysis.

Due to the implementation lag, the EPA cannot change policy until time $T$. After $T$, however, the regulator can-and will-impose the welfare maximizing tax given the state variables at the beginning of the period, $S(T)$ and $Z(T)$. It is clear that for $t>T$ the best tax to implement in the market economy is given by (14), where $\tau(t)$ is the shadow price of pollution characterised in (9) above. It follows that the only variable to be determined is the constant $\phi_{0}$, which pins down the optimal second-best tax that the EPA imposes at the time of implementation: $\theta^{S B}\left(T^{+}\right){ }^{7}$ Since, using (14), we can write that $\phi_{0}=\left[\theta^{S B}\left(T^{+}\right)-\right.$ $\tau(T)] \mathrm{e}^{-\rho T}$, once $\theta^{S B}\left(T^{+}\right)$is determined the whole second-best optimal tax path is simply:

$$
\theta^{S B}(t)= \begin{cases}\bar{\theta}(t), & \forall t \in[0, T) \\ \tau(t)+\left[\theta^{S B}\left(T^{+}\right)-\tau(T)\right] \mathrm{e}^{\rho(t-T)}, & \forall t \geq T\end{cases}
$$

where $\bar{\theta}(t)$ indicates any tax (or subsidy) stemming from pre-existing regulation that cannot be changed until time $T$. It is worth noting here that, in contrast with the first-best situation discussed in the previous section, in this case $\phi_{0}$ is uniquely determined, and hence there exists a unique level of the tax, $\theta^{S B}\left(T^{+}\right)$, that decentralizes the second-best optimal extraction path.

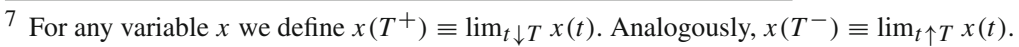


In order for the distinction between the first, constrained phase and the second, unconstrained phase to become more explicit, we can recast the EPA's problem as one of choosing the extraction path that maximises intertemporal welfare, defined as

$$
W=\int_{0}^{T}(U(R(t))-D(Z(t))) \mathrm{e}^{-\rho t} \mathrm{~d} t+\int_{T}^{\infty}(U(R(t))-D(Z(t))) \mathrm{e}^{-\rho t} \mathrm{~d} t,
$$

subject to the laws of motion of the resource stock and the stock of pollution-(2) and (3), respectively — and the behaviour of the private sector-(13) and (11).

Problem (16) highlights the interim and implementation phases, and can be solved by backwards induction recognizing that for any level of the resource and pollution stocks bequeathed to the second phase, $S(T)$ and $Z(T)$, the regulator's solution for $t \geq T$ parallels the one described in the previous section, accounting for the change in the planning horizonrecall (7) and (6). In other words, letting $V(S(T), Z(T))$ be the value function associated with the second stage, the maximand for the regulator's problem can be written as

$$
W=\int_{0}^{T}(U(R(t))-D(Z(t))) \mathrm{e}^{-\rho t} \mathrm{~d} t+V(S(T), Z(T)) \mathrm{e}^{-\rho T} .
$$

From (13), it follows that, if initial extraction is $R(0)=R_{0}$, then all subsequent extraction in the interim phase can be written as a function of $R_{0}$ and time only. Hence (13) implies:

$$
R(t)=\widetilde{R}\left(R_{0}, t\right) .
$$

From (2), it is clear that $R_{0}$ determines the time path of the resource stock,

$$
S(t)=S_{0}-\int_{0}^{t} \widetilde{R}\left(R_{0}, s\right) \mathrm{d} s \equiv \widetilde{S}\left(R_{0}, t\right),
$$

while (3) implies that $R_{0}$ also determines the time path of the stock of pollution,

$$
Z(t)=Z_{0}+\int_{0}^{t} \widetilde{R}\left(R_{0}, s\right) \mathrm{e}^{-\delta(t-s)} \mathrm{d} s \equiv \widetilde{Z}\left(R_{0}, t\right) .
$$

Transparently, the desired value of $V(S(T), Z(T))$ in (17) can be pinned down by an appropriate choice of $R_{0}$. The regulator cannot of course set this value directly. Instead, she has to set a tax path from time $T$ onwards that induces resource owners to follow the extraction path that maximises intertemporal welfare. Hence, the EPA's objective simplifies to implementing the optimal second-best $\operatorname{tax} \theta^{S B}(t)$ that induces the level of $R_{0}$ that maximises (17) subject to (11), (13), (19) and (20).

The optimal level of initial extraction $R_{0}$ then solves

$$
\begin{aligned}
\frac{\mathrm{d} W}{\mathrm{~d} R_{0}}= & \int_{0}^{T}\left[U^{\prime}(R(t)) \frac{\partial \widetilde{R}\left(R_{0}, t\right)}{\partial R_{0}}-D^{\prime}(Z(t)) \frac{\partial \widetilde{Z}\left(R_{0}, t\right)}{\partial R_{0}}\right] \mathrm{e}^{-\rho t} \mathrm{~d} t \\
& +\mathrm{e}^{-\rho T}\left[V_{S}(S(T), Z(T)) \frac{\partial \widetilde{S}\left(R_{0}, T\right)}{\partial R_{0}}+V_{Z}(S(T), Z(T)) \frac{\partial \widetilde{Z}\left(R_{0}, T\right)}{\partial R_{0}}\right]=0,
\end{aligned}
$$

where we let $V_{S}=\partial V / \partial S$, and $V_{Z}=\partial V / \partial Z$. To simplify the expression in (21), we first note that we can replace $U^{\prime}(R(t))$ using (13), which implies that for any point in time $t \geq 0$

$$
U^{\prime}(R(t))=\theta(t)+\left[U^{\prime}\left(R\left(T^{-}\right)\right)-\bar{\theta}\left(T^{-}\right)\right] \mathrm{e}^{-\rho(T-t)} .
$$

Secondly, we use the links between value function and shadow prices to replace $V_{Z}$ and $V_{S}$ in (21). Since at the margin the shadow cost of the stock of pollution needs to be equal to 
the reduction in welfare that ensues from a marginal increase of the stock at time $T$, we can write $-\tau(T)=V_{Z}(S(T), Z(T))<0$. Similarly, along the optimal path the shadow value of the stock of the resource should equal the increase in the value function that accompanies a marginal increase of the available resource, i.e. $\lambda(T)=V_{S}(S(T), Z(T))>0$. Substituting this into (4) and using (22), we get

$$
V_{S}(S(T), Z(T))=U^{\prime}\left(R\left(T^{-}\right)\right)-\bar{\theta}\left(T^{-}\right)+\theta^{S B}\left(T^{+}\right)+V_{Z}(S(T), Z(T)) .
$$

We now substitute (22) and (23) into (21) and rewrite to obtain an intermediate result for the optimal second-best tax to be implemented at the start of the second phase:

$$
\begin{aligned}
\theta^{S B}\left(T^{+}\right)= & -\mathrm{e}^{\rho T} \int_{0}^{T} \bar{\theta}(t) \frac{\mathrm{d} R(t)}{\mathrm{d} S(T)} \mathrm{e}^{-\rho t} \mathrm{~d} t+\mathrm{e}^{\rho T} \int_{0}^{T} D^{\prime}(Z(t)) \frac{\mathrm{d} Z(t)}{\mathrm{d} S(T)} \mathrm{e}^{-\rho t} \mathrm{~d} t \\
& +\tau(T)\left[1+\frac{\mathrm{d} Z(T)}{\mathrm{d} S(T)}\right]
\end{aligned}
$$

where we use ${ }^{8}$

$$
\frac{\mathrm{d} R(t)}{\mathrm{d} S(T)} \equiv \frac{\partial \widetilde{R}\left(R_{0}, t\right) / \partial R_{0}}{\partial \widetilde{S}\left(R_{0}, T\right) / \partial R_{0}}<0,
$$

which reflects how a marginal change in the policy affects the timing of extraction relative to total extraction during the interim phase, whereas

$$
\frac{\mathrm{d} Z(t)}{\mathrm{d} S(T)} \equiv \frac{\partial \widetilde{Z}\left(R_{0}, t\right) / \partial R_{0}}{\partial \widetilde{S}\left(R_{0}, T\right) / \partial R_{0}}<0
$$

reflects the fact that a marginal change in the policy affects the evolution of the pollution stock relative to total extraction during the interim phase.

Next, we apply integration by parts to (24) to find the second-best optimal tax rate to be implemented at the start of the second phase (see Appendix 2):

$$
\theta^{S B}\left(T^{+}\right)=\sigma(T)-\int_{0}^{T}[\sigma(t)-\bar{\theta}(t)]\left(-\frac{\mathrm{d} R(t)}{\mathrm{d} S(T)}\right) \mathrm{e}^{-\rho(t-T)} \mathrm{d} t .
$$

In the expression above, $\sigma(t)$ represents the discounted value of future marginal damages from carbon emitted at time $t$ :

$$
\sigma(t) \equiv \int_{t}^{\infty} D^{\prime}(Z(s)) \mathrm{e}^{-(\rho+\delta)(s-t)} \mathrm{d} s .
$$

We call $\sigma(t)$ the social cost of carbon. Note that, consistently with our discussion so far, after period $T$, the social cost of carbon coincides with the shadow cost of the pollution stock, i.e. $\sigma(t)=\tau(t)$ for $t \geq T$. However, in the interim period $t<T$, emissions deviate from their first-best level and $\sigma$ and $\tau$ differ. Hence, for $t \leq T$ we may write:

$$
\sigma(t)=\int_{t}^{T} D^{\prime}(Z(s)) \mathrm{e}^{-(\rho+\delta)(s-t)} \mathrm{d} s+\mathrm{e}^{-\rho(T-t)} \tau(T) .
$$

Equation (27) characterizes the second-best optimal tax rate: as discussed in (15), the second-best tax is composed on the first-best tax and a correction that addresses the distortions in the model.

8 More information on (25) and (26) can be found in Appendix 1. 
Abstracting for the moment from pre-existing taxes, the integral at the right-hand side of (27) informs us that, since an abundance effect arises from the unavoidable implementation lag, the second-best tax will normally be lower than the first-best carbon price in order to reduce the damages caused by the front-loading of extraction. The strength of the correction depends, however, on the strength of the abundance effect: at the optimum the second-best tax trades off avoided damages from reduced emissions - measured by the social cost of carbonagainst the forgone use of the resource — captured by the derivative in the parentheses. ${ }^{9}$

Furthermore, the integral at the right-hand side of (27) emphasizes the role of pre-existing taxes. Indeed, if such taxes are close to the social cost of carbon, the second-best correction is small and the second-best tax starts very close to the social cost of carbon. Intuitively, given that pre-existent taxes are almost 'as good as' an optimal carbon tax, the result cannot be far from the first-best. In the more relevant case where pre-existing taxes are significantly lower than the social cost of carbon, i.e. with insufficient carbon pricing, we have $\sigma>\bar{\theta}$. According to the optimal tax rule in (27) the optimal second-best $\operatorname{tax} \theta^{S B}\left(T^{+}\right)$must now be set below the social cost of carbon after the interim phase.

This discussion confirms our intuition at the beginning of the section that the regulator would try to modify the Pigouvian tax to minimize the welfare costs from pre-existing distortions and the abundance effects. By setting a lower future tax, emissions are shifted from the interim phase, during which they are insufficiently priced, towards the later period, during which pricing fully reflect damages. In the next section we discuss various cases in more detail to see the implications of our general optimal tax rule (27).

\section{Anatomy of the Corrective Tax}

\subsection{Correcting for Pre-existing Taxes}

We start by focussing on the role of pre-existing policies. To do this, we assume that no damages arise from the pollution stock, i.e. we let $D(Z(t))=0$ for any $Z(t)$, so that $\tau(t)=0$ and $\sigma(t)=0$.

Let us first determine under which conditions pre-existing taxes are distortionary. Recall that, from (13), during the interim phase we must have for all $t_{1}<t_{2}<T$ that:

$$
\left[U^{\prime}\left(R\left(t_{1}\right)\right)-\bar{\theta}\left(t_{1}\right)\right] \mathrm{e}^{-\rho t_{1}}=\left[U^{\prime}\left(R\left(t_{2}\right)\right)-\bar{\theta}\left(t_{2}\right)\right] \mathrm{e}^{-\rho t_{2}} .
$$

Furthermore, recall that, from (7), in the first-best without damages (i.e. with $\tau=0$ ) we must have that

$$
\left[U^{\prime}\left(R\left(t_{1}\right)\right)\right] \mathrm{e}^{-\rho t_{1}}=\left[U^{\prime}\left(R\left(t_{2}\right)\right)\right] \mathrm{e}^{-\rho t_{2}} .
$$

To see how a certain time path of the pre-existing tax may be non-distortionary, it is illuminating to consider taxes that exhibit a constant growth rate $g$. Thus, let $\bar{\theta}\left(t_{2}\right)=\bar{\theta}\left(t_{1}\right) \mathrm{e}^{g\left(t_{2}-t_{1}\right)}$. As long as $g=\rho$, (29) implies (30) and the tax induces an optimal extraction and consumption path. If, however, the tax grows at a rate different from $\rho$ between any two points in time $t_{1}$ and $t_{2}$, then (29) does not collapse to (30), the tax is indeed distortionary, and welfare is not maximized (see e.g. Burness 1976).

9 The strength of the abundance effect depends on the price elasticity of demand, which is reflected in the size of the derivative with respect to the resource stock at time $T, S(T)$. Intuitively, when the demand for the resource is very elastic, more of the resource can be absorbed by the market as the price falls. For detailed discussions of the effects of demand and supply elasticities on the size of the abundance effect, see Di Maria et al. (2014a, b) and Van der Ploeg (2016). 
In the presence of a pre-existing distortionary tax (or subsidy), the regulator may wish to reduce the impact of the resulting distortion on welfare by announcing at the start of the planning horizon a corrective tax to be implemented from time $T$ onward. When there are no damages associated with the stock of pollution, $\sigma(t)=0$ and Eq. (27) can be written as (see Appendix 3):

$$
\theta^{S B}\left(T^{+}\right)=\bar{\theta}\left(T^{-}\right)-\mathrm{e}^{\rho T} \int_{0}^{T}[\dot{\bar{\theta}}(t)-\rho \bar{\theta}(t)] \frac{\mathrm{d} S(t)}{\mathrm{d} S(T)} \mathrm{e}^{-\rho t} \mathrm{~d} t .
$$

The last expression confirms that the regulator would optimally adjust the tax if and only if it is distortive, i.e. if the value of the integral at the right-hand side of (31) is different from zero. For example, if the pre-existing tax $\bar{\theta}(t)$ were to grow over time at a rate faster than $\rho$, it would induce a front-loading of extraction as expected profits would be smaller later in the planning horizon. Under these circumstances, the integral in (31) is positive suggesting that it is optimal to reduce taxes in the second phase. By making future extraction more attractive, this correction reduces the incentives to front-load extraction.

While the growth rate of the pre-existing tax determines the degree of inefficient allocation within the interim phase, the time path of the tax level determines the degree of inefficient allocation across the two periods, i.e. across the interim phase and the phase starting at time $T$. The effect of the level of the pre-existing tax is included in the level of the optimal second-best tax through the $\bar{\theta}\left(T^{-}\right)$term in (31).

\subsection{Correcting for Climate Damages}

We now assume away pre-existing taxes to better focus on the role of climate damages, starting with the extreme case in which the carbon stock does not decay over time. We thus let $\delta=0$, so that $\mathrm{d} Z(t)=-\mathrm{d} S(t)$. Without carbon decay, the optimal 'initial' tax can be directly inferred from (24):

$$
\theta^{S B}\left(T^{+}\right) \mathrm{e}^{-\rho T}=-\int_{0}^{T} D^{\prime}(Z(t))\left(-\frac{\mathrm{d} Z(t)}{\mathrm{d} S(T)}\right) \mathrm{e}^{-\rho t} \mathrm{~d} t .
$$

Since the integral on the right-hand side is unambiguously positive, the equation shows that in the absence of pre-existing taxation it is optimal to impose a subsidy to resource extraction after the interim phase.

This is because the subsidy introduces an incentive for resource owners to reduce extraction in the interim period and postpone extraction to the period in which they can reap a subsidy. Intuitively, this is optimal for the EPA since it shifts emissions from a period in which externalities are unpriced, to the period in which they are appropriately priced.

While the sign of the tax is unambiguously negative in this case, the size of the tax depends on many factors. A substantial subsidy at the time of implementation entails a substantial loss in terms of foregone resource use during the interim phase, which can only be justified if the avoided damages during the interim are substantial. Indeed, the above equation suggests that the subsidy is likely to be bigger if marginal damages, the discount rate and the length of the interim phase are larger.

\subsubsection{When Marginal Damages are Constant}

We now take an additional step and let $\delta>0$ (we still abstract from pre-existing taxes, i.e. $\bar{\theta}=0$ ). Initially, however, in the interest of simplicity we assume that marginal damages are 
constant and equal to $\alpha$. As already mentioned in Sect. 2, this implies, from (9), that $\tau(t)$ is constant over time and equal to $\alpha /(\rho+\delta)$. Accordingly, (27) simplifies to (see Appendix 3):

$$
\theta^{S B}\left(T^{+}\right)=-\left(\frac{\alpha}{\rho+\delta}\right)\left[\rho \int_{0}^{T}\left(\frac{\mathrm{d} S(t)}{\mathrm{d} S(T)}\right) \mathrm{e}^{-\rho(t-T)} \mathrm{d} t\right] .
$$

In this case the optimal second-best tax consists of the Pigouvian tax at $T$, times a factor (the term in brackets) reflecting the sensitivity of extraction during the interim phase. Since the right-hand side expression is negative, we again find that the second-best tax at the time of implementation is negative. Intuitively it is clear why this is so: it is necessarily welfare improving in this situation to shift some of the uncorrected emissions from the interim phase to the regulated phase. Notice that the term in brackets increases with $T$, so that we can conclude that a longer interim phase requires a higher subsidy. Intuitively, a longer period with insufficient carbon pricing has to be offset by a higher tax incentive to postpone emissions.

\subsubsection{When Marginal Damages are Increasing}

Finally, let us consider the more general situation in which marginal damages rise with the size of the stock of pollution.

When marginal damages are not constant the timing of emissions matters, which changes the nature of the corrective tax. For example, when marginal damages are extremely convex, emissions early in the interim phase are not quite as costly as with constant marginal damages, and thus do not require an excessive reduction in extraction and the associated loss of utility from resource consumption. In this sense Eq. (27) emphasizes that there might be two opposing forces at work here. On the one hand, there is an incentive to reduce the net present value of damages during the interim phase - this is the effect discussed in Sect. 4.2.1 —and it is optimal to subsidize extraction in the second phase. On the other hand, with convex damages, the marginal damages at $T$ are higher than during the interim phase. This provides a reason to limit the shift of extraction from the interim phase to time $T$. It turns out, however, that this second effect never fully offsets the first one, and the corrective tax is always a subsidy in the absence of further distortions from pre-existing taxation.

In this case of convex marginal damages, $\sigma$ is no longer a constant. To assess the implication formally, we again abstract from pre-existing taxes and rewrite (27) as (see Appendix 3)

$$
\theta^{S B}\left(T^{+}\right)=\int_{0}^{T}(\dot{\sigma}(t)-\rho \sigma(t))\left(\frac{\mathrm{d} S(t)}{\mathrm{d} S(T)}\right) \mathrm{e}^{-\rho(t-T)} \mathrm{d} t .
$$

If the social cost of carbon falls over time, the expression is unambiguously negative and we again find the result that the EPA implements a subsidy at the start of the regulation period. Notice however that even in the case in which the social cost of carbon rises during the implementation period, i.e. when damages are convex, the EPA chooses a subsidy. Indeed, we now argue that the integral must be negative. To see this, we note that the integral is by construction evaluated at the second-best optimal path. If along the optimal path the social cost would grow at a rate bigger than the discount rate, the integral would be positive indicating that the EPA finds it optimal to introduce a tax. In this case, however, the discounted net cost of extraction, $\left(U^{\prime}(R(t))-\sigma(t)\right) \mathrm{e}^{-\rho t}$, would fall over time and the planner would optimally choose to exhaust the resource at time zero. This would, however, leave no resource to be extracted in the implementation period indicating that there would be no need for a tax in the first place. Hence, there is a contradiction and the social cost of carbon cannot grow faster than the rate of discount so that the integral is always negative. 
In concluding this section we note that, while it clearly emerges that in the absence of pre-existing taxation we can conclude that the EPA would always find it optimal to introduce a subsidy to extraction at the start of the implementation phase, in the presence of pre-existing taxes it is in general not possible to univocally determine the sign of $\theta^{S B}\left(T^{+}\right)$. The sign and the magnitude of the optimal second-best tax in this case is a purely empirical matter.

\section{Discussion and Conclusion}

The prices of polluting inputs, particularly fossil-based energy, have been shown to be among the key drivers of 'green' innovation (e.g. Popp 2002; Aghion et al. 2016; Noailly and Smeets 2015). In the presence of distortions that depress the price of polluting inputs the process of innovation may slow down and the transition to cleaner energy sources may be hampered. Earlier research has shown that the presence of an implementation lag in environmental policy suppresses resource prices (Di Maria et al. 2012, 2014b) as the announcement of a future resource price gives resource owners an incentive to frontload extraction. This not only reduces the incentives for green innovation, but also leads to an increase in early emissions (cf. Sinn 2008).

We have shown that when a regulator cannot adjust regulation for a given period to come, she should let her announced and implemented policy reflect the incentives stemming from an implementation lag. We have discussed why it is optimal to adjust the standard carbon tax à la Withagen (1994) to account for the level and the time profile of pre-existing taxes, the overall size of the frontloaded extraction, and the shape of the marginal damage function. Indeed, we conclude that in the presence of implementation lags and pre-existing policy, it might be optimal to reduce the carbon tax below the level of the Pigouvian tax, or even to subsidize the consumption of fossil fuels in the future. Interestingly, we find that while the first-best extraction path can be implemented by a continuum of resource taxes, in the presence of implementation lags, there typically exists a unique path that decentralizes the optimal (second-best) extraction path. Thus implementation lags and carbon pricing restrict the regulator's ability to extract rents from the resource owners.

From the empirical point of view, however, it seems that a scenario with pre-existing taxes with a negative net present value, i.e. pre-existing subsidies, is likely to be the most relevant one. Coady et al. (2015), for example, estimate global subsidies to fossil fuel consumption in 2015 to be USD 5.3 trillion, or $6.5 \%$ of global GDP. These subsidies include explicit subsidies for consumption as well as implicit subsidies such as not internalizing the damages on the local and global environment. Indeed, the authors estimate that USD 2.4 trillion stems from not internalizing local air pollution from coal consumption and USD 750 billion from not internalizing climate damages from coal consumption. In recent years, the mounting pressure on governments to abolish these subsidies has lead to a decline in such subsidies (Coady et al. 2015). Their slow reduction, however, testifies of the challenges to reform efforts in the real world. On the face of this evidence, we conclude that, in the parlance of our model, the real world counterpart of the pre-existing taxes $\theta(t)$ is likely to be negative and with a positive slope. This fact may be taken to indicate that, based on the letter of our model, the optimal second-best tax would in reality be a subsidy to the future consumption of fossil fuels.

If the optimal second-best tax is negative, it shifts extraction and emissions from the interim phase to the period thereafter. In doing so, it increases the user price of polluting resources in the interim phase by increasing the rents that resource owners can obtain. This increase in the user price in turn increases the incentives for green innovation. It should be 
noted, however, that the optimal second-best tax reduces future resource prices and may thereby have a negative effect on the incentives for innovation. What the net effect of these two opposing forces, as well as of the length of the interim phase $T$, is on green innovation is an important question for future research.

It is worth noting that in this paper we have abstracted from the economic depreciation of the resource stock, i.e. we have ignored the possibility that extraction costs be stockdependent (cf. Heal 1976). As resource taxation and innovation both affect the size of the resource stock that is ultimately extracted, an interesting, complementary line for further research would be to analyse the effect of this more realistic way of modelling extraction costs.

Open Access This article is distributed under the terms of the Creative Commons Attribution 4.0 International License (http://creativecommons.org/licenses/by/4.0/), which permits unrestricted use, distribution, and reproduction in any medium, provided you give appropriate credit to the original author(s) and the source, provide a link to the Creative Commons license, and indicate if changes were made.

\section{Appendix 1: Intermediate Steps to Find (24)}

Substituting (18) into (13) and differentiating with respect to $R_{0}$, we find

$$
\frac{\partial \widetilde{R}\left(R_{0}, t\right)}{\partial R_{0}}=\frac{U^{\prime \prime}\left(R_{0}\right)}{U^{\prime \prime}(R(t))} \mathrm{e}^{\rho t}>0,
$$

which implies that a marginal increase in extraction at time 0 entails an increase in extraction at each point in time during the interim phase.

Differentiating (19) with respect to $R_{0}$ further yields:

$$
\frac{\partial \widetilde{S}\left(R_{0}, t\right)}{\partial R_{0}}=-\int_{0}^{t} \frac{\partial \widetilde{R}\left(R_{0}, s\right)}{\partial R_{0}} \mathrm{~d} s<0
$$

whereas from (20) we get:

$$
\frac{\partial \widetilde{Z}\left(R_{0}, t\right)}{\partial R_{0}}=\int_{0}^{t} \frac{\partial \widetilde{R}\left(R_{0}, s\right)}{\partial R_{0}} \mathrm{e}^{\delta(s-t)} \mathrm{d} s>0 .
$$

\section{Appendix 2: Integration by Parts to Find (27)}

First we rewrite (24), multiplying both sides by $\mathrm{e}^{-\rho t}$, using $\tau(T)=\sigma(T)$, as follows:

$$
\begin{aligned}
\theta^{S B}\left(T^{+}\right) \mathrm{e}^{-\rho T}= & -\int_{0}^{T} \bar{\theta}(t) \dot{w}(t) f(t) \mathrm{d} t+\int_{0}^{T} D^{\prime}(Z(t)) q(t) f(t) \mathrm{d} t \\
& +f(T) \sigma(T)[1+q(T)],
\end{aligned}
$$


where the new variables $f, q, w$ are defined as:

$$
\begin{aligned}
f(t) & \equiv \mathrm{e}^{-\rho t}, \\
q(t) & \equiv \frac{\mathrm{d} Z(t)}{\mathrm{d} S(T)} \equiv \frac{\partial \widetilde{Z}\left(R_{0}, t\right) / \partial R_{0}}{\partial \widetilde{S}\left(R_{0}, T\right) / \partial R_{0}}<0, \\
-w(t) & \equiv \frac{\mathrm{d} S(t)}{\mathrm{d} S(T)} \equiv \frac{\partial \widetilde{S}\left(R_{0}, t\right) / \partial R_{0}}{\partial \widetilde{S}\left(R_{0}, T\right) / \partial R_{0}}>0 .
\end{aligned}
$$

From these definitions we find:

$$
\begin{gathered}
\dot{w}(t)=\frac{\mathrm{d} R(t)}{\mathrm{d} S(T)} \equiv \frac{\partial \widetilde{R}\left(R_{0}, t\right) / \partial R_{0}}{\partial \widetilde{S}\left(R_{0}, T\right) / \partial R_{0}}<0 . \\
q(0)=w(0)=0, \\
-w(T)=f(0)=1,
\end{gathered}
$$

and

$$
\dot{q}(t)=\dot{w}(t)-\delta q(t) .
$$

The second term on the right-hand side of $\left(24^{\prime}\right)$ can be written as

$$
\begin{aligned}
\int D^{\prime} q f & =\int[(\delta+\rho) \sigma-\dot{\sigma}] q f \\
& =\delta \int \sigma q f-\int \sigma q \dot{f}-\int \dot{\sigma} q f \\
& =\delta \int \sigma q f-[\sigma q f]+\int \sigma \dot{q} f \\
& =\delta \int \sigma q f-[\sigma q f]+\int \sigma(\dot{w}-\delta q) f \\
& =-[\sigma q f]+\int \sigma \dot{w} f
\end{aligned}
$$

Taking the integral over $[0, T]$, we find

$$
\int_{0}^{T} D^{\prime}(Z(t)) q(t) f(t) \mathrm{d} t=-\sigma(T) q(T) f(T)+\int_{0}^{T} \sigma(t) \dot{w}(t) f(t) \mathrm{d} t
$$

Substituting this in Eq. $\left(24^{\prime}\right)$ and converting back to original variables we find (27).

\section{Appendix 3: Derivation of (31), (32) and (33)}

The first term on the right-hand side of $\left(24^{\prime}\right)$ can be written as

$$
\int_{0}^{T} \bar{\theta}(t) \dot{w}(t) f(t) \mathrm{d} t=[\bar{\theta}(t) w(t) f(t)]_{0}^{T}-\int_{0}^{T} \dot{\bar{\theta}}(t) w(t) f(t) \mathrm{d} t-\int_{0}^{T} \bar{\theta}(t) w(t) \dot{f}(t) \mathrm{d} t .
$$

Solving the right-hand side of this equation and multiplying it by $\mathrm{e}^{\rho T}$ gives

$$
\int_{0}^{T} \bar{\theta}(t)\left(-\frac{\mathrm{d} R(t)}{\mathrm{d} S(T)}\right) \mathrm{e}^{-\rho t} \mathrm{~d} t=\mathrm{e}^{-\rho T} \bar{\theta}\left(T^{-}\right)-\int_{0}^{T}[\dot{\bar{\theta}}(t)-\rho \bar{\theta}(t)] \frac{\mathrm{d} S(t)}{\mathrm{d} S(T)} \mathrm{e}^{-\rho t} \mathrm{~d} t,
$$

which, when substituted into (27) and in the absence of climate damages, gives expression (31) in the main text. 
Similarly, integration by parts of the right-hand side of (27) gives expression (33) in the main text. When marginal damages are constant, we know that $\sigma(t)=\frac{\alpha}{\rho+\delta}$. In this case (33) simplifies to (32).

\section{References}

Acemoglu D, Aghion P, Bursztyn L, Hemous D (2012) The environment and directed technical change. Am Econ Rev 102:131-166

Aghion P, Dechezleprêtre A, Hémous D, Martin R, Van Reenen J (2016) Carbon taxes, path dependency and directed technical change: evidence from the auto industry. J Polit Econ 124:1-51

Burness H (1976) On the taxation of nonreplenishable natural resources. J Environ Econ Manag 3:289-311

Calel R, Dechezleprêtre A (2016) Environmental policy and directed technological change: evidence from the European carbon market. Rev Econ Stat 98:173-191

Coady D, Parry I, Sears L, Shang B (2015) How large are global energy subsidies? IMF Working Paper WP/15/105

D’Arge R, Kogiku K (1973) Economic growth and the environment. Rev Econ Stud 40:61-77

Davis LW (2014) The economic cost of global fuel subsidies. Am Econ Rev 104:581-585

Di Maria C, Smulders S, Van der Werf E (2012) Absolute abundance and relative scarcity: environmental policy with implementation lags. Ecol Econ 74:104-119

Di Maria C, Lange I, Van der Werf E (2014a) Going full circle: demand side constraints to the Green Paradox. In: Pittel K, Withagen C, Van der Ploeg R (eds) The green paradox and beyond. MIT Press, Cambridge

Di Maria C, Lange I, Van der Werf E (2014b) Should we be worried about the green paradox? Announcement effects of the Acid Rain Program. Eur Econ Rev 69:143-162

Eichner T, Pethig R (2011) Carbon leakage, the green paradox and perfect future markets. Int Econ Rev 52:767-805

Forster B (1980) Optimal energy use in a polluted environment. J Environ Econ Manag 7:321-333

Gaudet G, Lasserre P (2015) The taxation of nonrenewable natural resources. In: Halvorsen R, Layton D (eds) Handbook on the economics of natural resources. Edward Elgar, Cheltenham

Gerlagh R (2011) Too much oil. CESifo Econ Stud 57:79-102

Grimaud A, Lafforgue G, Magné B (2011) Climate change mitigation options and directed technical change: a decentralized equilibrium analysis. Resour Energy Econ 33:938-962

Heal G (1976) The relationship between price and extraction cost for a resource with a backstop technology. Bell J Econ 7:371-378

Hoel M, Kverndokk S (1996) Depletion of fossil fuels and the impacts of global warming. Resour Energy Econ 18:115-136

Mattauch L, Creutzig F, Edenhofer O (2015) Avoiding carbon lock-in: policy options for advancing structural change. Econ Model 50:49-63

Noailly J, Smeets R (2015) Directing technical change from fossil-fuel to renewable energy innovation: an application using firm-level patent data. J Environ Econ Manag 72:15-37

OECD (2011) Towards green growth. Organization for Economic Cooperation and Development, Paris

Popp D (2002) Induced innovation and energy prices. Am Econ Rev 92:160-180

Sinclair P (1992) High does nothing and rising is worse: carbon taxes should keep declining to cut harmful emissions. Manch Sch LX:41-52

Sinn H (2008) Public policies against global warming. Int Tax Pub Financ 15:360-394

Tahvonen O (1997) Fossil fuels, stock externalities, and backstop technology. Can J Econ 30:855-874

Ulph A, Ulph D (1994) The optimal time path of a carbon tax. Oxf Econ Pap 46:857-868

UNEP (2011) Towards a green economy: pathways to sustainable development and poverty eradication, United Nations Environment Programme

Van der Ploeg F (2016) Second-best carbon taxation in the global economy: the Green Paradox and carbon leakage revisited. J Environ Econ Manag 78:85-105

Van der Ploeg F, Withagen C (2012) Is there really a Green Paradox? J Environ Econ Manag 64:342-363

WCED (1987) Our common future. Oxford University Press, Oxford

Withagen C (1994) Pollution and exhaustibility of fossil fuels. Resou Energy Econ 16:235-242 